Article

\title{
Cavitation Erosion and Sliding Wear Mechanisms of AlTiN and TiAlN Films Deposited on Stainless Steel Substrate
}

\author{
Mirosław Szala ${ }^{1, *(\mathbb{D}}$, Mariusz Walczak ${ }^{1}$, Kamil Pasierbiewicz ${ }^{1,2}$ and Mariusz Kamiński ${ }^{3}$ (i) \\ 1 Department of Materials Engineering, Faculty of Mechanical Engineering, Lublin University of Technology, \\ Nadbystrzycka 36D, 20-618 Lublin, Poland; m.walczak@pollub.pl (M.W.); pasierbiewicz.k@gmail.com (K.P.) \\ 2 Faculty of Transport and Computer Science, University of Economics and Innovation, Projektowa 4, \\ 20-209 Lublin, Poland \\ 3 Department of Automotive Vehicles, Faculty of Mechanical Engineering, Lublin University of Technology, \\ Nadbystrzycka 36D, 20-618 Lublin, Poland; mariusz.kaminski@pollub.pl \\ * Correspondence: m.szala@pollub.pl; Tel.: +48-815-384-209
}

Received: 18 April 2019; Accepted: 23 May 2019; Published: 25 May 2019

\begin{abstract}
The resistance to cavitation erosion and sliding wear of stainless steel grade AISI 304 can be improved by using physical vapor deposited (PVD) coatings. The aim of this study was to investigate the cavitation erosion and sliding wear mechanisms of magnetron-sputtered AlTiN and TiAlN films deposited with different contents of chemical elements onto a stainless steel SS304 substrate. The surface morphology and structure of samples were examined by optical profilometry, light optical microscopy (LOM) and scanning electron microscopy (SEM-EDS). Mechanical properties (hardness, elastic modulus) were tested using a nanoindentation tester. Adhesion of the deposited coatings was determined by the scratch test and Rockwell adhesion tests. Cavitation erosion tests were performed according to ASTM G32 (vibratory apparatus) in compliance with the stationary specimen procedure. Sliding wear tests were conducted with the use of a nano-tribo tester, i.e., ball-on-disc apparatus. Results demonstrate that the cavitation erosion mechanism of the TiAlN and AlTiN coatings rely on embrittlement, which can be attributed to fatigue processes causing film rupture and internal decohesion in flake spallation, and thus leading to coating detachment and substrate exposition. At moderate loads, the sliding wear of thin films takes the form of grooving, micro-scratching, micro-ploughing and smearing of the columnar grain top hills. Compared to the SS reference sample, the PVD films exhibit superior resistance to sliding wear and cavitation erosion.
\end{abstract}

Keywords: cavitation erosion; sliding wear; thin film; AlTiN; TiAlN; mechanical properties; stainless steel; magnetron sputtering; wear mechanism

\section{Introduction}

Stainless steel grade AISI 304 (SS) is one of the most widely used modern structural materials due to its high corrosion resistance, satisfactory mechanical properties, sufficient weldability and good formidability [1-6]. However, its sliding wear and cavitation erosion resistance (CER) is limited. The wear resistance of SS can be improved by depositing different systems of hard coatings, such as TiN, $\mathrm{CrN}$, TiAlN, AlTiN or AlCrN, or even by depositing stainless steel coatings enriched with silver [3,7-10]. Modern types of TiAlN or AlTiN hard films are widely used for manufacturing machining tools or machine components to reduce their tribochemical and adhesive wear, or to make them resistant to severe thermal conditions. In other words, the use of AlTiN and TiAlN coatings (with different ratios of $\mathrm{Al} /(\mathrm{Ti}+\mathrm{Al})$ ) can be an effective way of increasing the wear resistance of stainless steel components exposed to severe wear processes [9-15]. Moreover, universal ternary coating systems such as TiAlN 
or AlTiN can not only improve the tribological properties of a substrate, but can also be used to create a protective layer on steel components subjected to cavitation erosion, and thus enhance their cavitation erosion resistance.

A survey of the literature on the cavitation erosion (CE) of binary coating systems demonstrates that hard thin films such as TiN, CrN have a higher CER than the SS304 substrate [7,16]. In turn, ternary film systems usually exhibit superior mechanical properties to binary coating systems. Also, it is stated in the literature $[7,17]$ that, besides film properties, mechanical properties of the substrate are crucial for CER and physical vapor deposited (PVD) coatings too. In addition, there are studies investigating the CE of aluminum alloy coated with a thin TiAlN film [17]. However, there are no studies on the cavitation erosion mechanism of TiAlN or AlTiN in relation to the properties of the SS304 substrate. Also, there is a limited number of studies comparing the properties of TiAlN or AlTiN coatings in relation to their cavitation erosion resistance and investigating their $\mathrm{CE}$ wear mechanisms. Additionally, it is worth investigating the cavitation wear resistance of TiAlN and AlTiN in order to determine whether the chemical composition differences (i.e., $\mathrm{Al} /(\mathrm{Ti}+\mathrm{Al})$ ratio) have any effect on their CER.

The nanoindentation results (i.e., hardness and elastic modulus) reported in the literature primarily concern samples before cavitation testing [7,17]. In this work, the relationship between the evolution of mechanical properties of a coating and CE testing is investigated to estimate the cavitation erosion wear mechanism of the magnetron-sputtered films. This is a quite novel approach to film cavitation erosion evaluation.

TiAlN and AlTiN films can easily be applied on various substrates, and are widely used in machine building for preventing from tribological wear. These coatings are known to operate well under high load conditions [9-14]. However, their sliding wear mechanism under moderate load conditions has not been sufficiently reported in the literature.

The aim of this work is to investigate the cavitation erosion and sliding wear under moderate load of magnetron-sputtered AlTiN and TiAlN coatings deposited on a stainless steel substrate. The paper is an introduction to the CER testing of films deposited on various metal alloy substrates and attempt at quantitative determination of their CER. It is proposed that thin films such as TiAlN or AlTiN be applied in fluid machinery, precise mechanics and engine manufacturing as a method for preventing cavitation wear.

\section{Materials and Methods}

AlTiN and TiAlN films were deposited with different contents of chemical elements on a stainless steel substrate (grade AISI 304) by using DC magnetron sputtering to obtain approx. $3 \mu \mathrm{m}$ thick layers. The substrate roughness was lower than $S a=0.2 \mu \mathrm{m}$. After deposition, several properties were identified. Thickness of the coatings was examined with a Calotester (surface testing), and metallographic examination on the sample sections was performed by light optical microscopy (LOM, Nikon MA200, Nikon Corporation) (Tokyo, Japan), Scanning electron microscopy (SEM, Quanta, Thermo Fisher Scientific-FEI, and Phenom World ProX, BSE, topographic modes and EDS, Phenom World) (Waltham, MA, USA) and an optical profiler (ContourGT-X 3D Optical Profiler, Bruker Corporation, Billerica, MA, USA) were employed to examine structure, surface morphology, chemical composition and roughness of the coatings. The deposited nitride films and mechanical properties of the substrate were tested on the top sample surfaces using an Ultra Nanoindentation Tester (Anton Paar GmbH, Ostfildern, Germany), in compliance with the procedures described in [18]. Hardness $H$ and elastic modulus $E$ were calculated from the indentation load-displacement data by the Oliver Pharr method [19,20]. In accordance with the literature of the subject [14,21-23], the indentation depth was maintained below $10 \%$ of the coating thickness. It should be noted that, out of approx. Out of 80 indentations made, only approx. $80 \%-90 \%$ of the results were considered to estimate mechanical properties of the films. Adhesion of the deposited coatings was determined by scratch testing and Rockwell adhesion tests. The scratch tests were performed on a Micro Combi Tester (Anton Paar 
GmbH, Ostfildern, Germany) [24] while the Rockwell adhesion tests $[15,25]$ were conducted according to the VDI 3198 procedure.

Cavitation erosion and sliding wear tests were conducted on bare stainless steel grade SS304 (SS) and SS samples coated with PVD films. Cavitation erosion tests were performed according to ASTM G32 [26] (vibratory apparatus), in compliance with the stationary specimen procedure. The test procedure was described in previous work [27], while a schematic design of the apparatus is shown in Figure 1 . The specimen is mounted in the holder and submerged in distilled water. Horn tip vibrations generate a cavitation field that causes erosion of the specimen surface (Figure 1). In the present study, a sonotrode tip with a $15.9 \mathrm{~mm}$ diameter was used. Damaged samples were examined by weighing with a $0.1 \mathrm{mg}$ accuracy balance. Worn surface roughness was measured with an optical profilometer and examined by the SEM-EDS method and optical microscopy (OM, stereoscope microscope Nikon SMZ 1500) (Tokyo, Japan). The cavitation-worn area was measured with the ImagePro computer image analysis software (Media Cybernetics, Inc., Rockville, MD, USA) and captured as OM images [28]. During $4.5 \mathrm{~h}$ of cavitation, normalized cavitation erosion resistance was calculated by dividing the estimated indicators of SS304 by estimated indicators of the AlTiN and TiAlN films, based on the results of sample weighing (mass loss), computer image analysis of worn surfaces (\% of the damaged area) and surface roughness (roughness parameter Sa). Additionally, a new concept for describing the $\mathrm{CE}$ effect on the deposited films was proposed, i.e., nanoindentation measurement of the $\mathrm{H}$ and $\mathrm{E}$ parameters of the sample surface before and after cavitation erosion testing. In this way, the observed changes in the film properties could be used for CER mechanism description.

To simulate moderate friction conditions describing mostly limited sliding loads in fluid machinery, the nano-tribo tests were performed with the use of the NTR2 nano-tribometer from Anton Paar $\mathrm{GmbH}[29,30]$. A WC ball with a $0.5 \mathrm{~mm}$ diameter was used as the counterpart. A load of $0.8 \mathrm{~N}$, a sliding distance of $90 \mathrm{~m}$ and a sliding radius of $5 \mathrm{~mm}$ were applied to the ball. As a result, the friction coefficient $\mu$ of individual samples could be determined. Next, the wear trace of individual samples was measured using the Taylor Hobson Form Talysurf Intra profile measurement gauge. The measurements provided profilograms enabling determination of the wear factor $K$, see [31]. In addition, obtained wear traces were analyzed with SEM to identify the mechanism of wear.

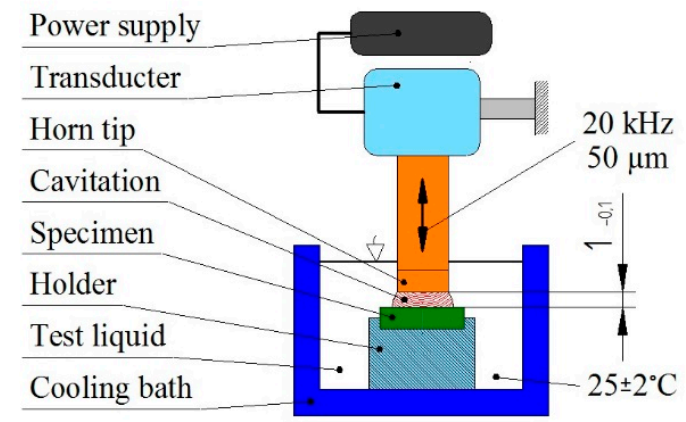

Figure 1. Design of a vibratory apparatus for cavitation tests.

\section{Results and Discussion}

\subsection{Description of Film Properties in Relation to Stainless Steel Substrate}

The wear resistance of thin films should be discussed in relation to the structure and properties of the film and substrate alike. In the present work, the thickness of the magnetron-sputtered films measured with a Calotester agrees with the findings of cross-section metallographic examination, amounting to $\approx 2.7 \mu \mathrm{m}$ for TiAlN and $\approx 3.8 \mu \mathrm{m}$ for AlTiN. The coatings show a dense compact structure (Figure 2) characterized by columnar growth which according to Kalss [32] —is typical of the sputtering technique. The coatings' roughness measured with a profilometer was lower than $0.2 \mu \mathrm{m}$, which corresponds to surface preparation of the stainless steel substrate. 
This preliminary study investigates the influence of differences in the chemical composition of AlTiN and TiAlN films on the films wear behavior. Chemical compositions of the films are compared in Table 1, showing that the AlTiN film contains more aluminum and nitrogen than the TiAlN film. Both the $\mathrm{Al}$ content and $\mathrm{Al} /(\mathrm{Ti}+\mathrm{Al})$ ratio play an important role in increasing film mechanical properties [9,14]. Therefore, the higher average film-to-SS substrate adhesion of AlTiN (Table 2) can be explained by a higher $\mathrm{Al}$ content. It can be claimed that the differences in the chemical composition of AlTiN and TiAlN affect the mechanical properties of these films, as well as the substrate-to-film performance and, finally, functional properties such as wear resistance.

Moreover, a statistical analysis of the Lc2 values and scratch trace (Figures 3 and 4) reveals a satisfactory degree of adhesion for both films. In Figure 3 conformal cracking, cohesive failure and microcracks are visible, while from Figure 4 it can be concluded that the main adhesive failure modes are cohesive failure, spallation and tensile micro-cracking followed by chipping failure of the AlTiN and TiAlN films, which agrees with the results reported for films deposited on SS substrate [12]. Additionally, Figure 4 shows finer cracking of the TiAlN film than the AlTiN, which may result from variations in the coating's elasticity modulus, film adhesion and cohesion.

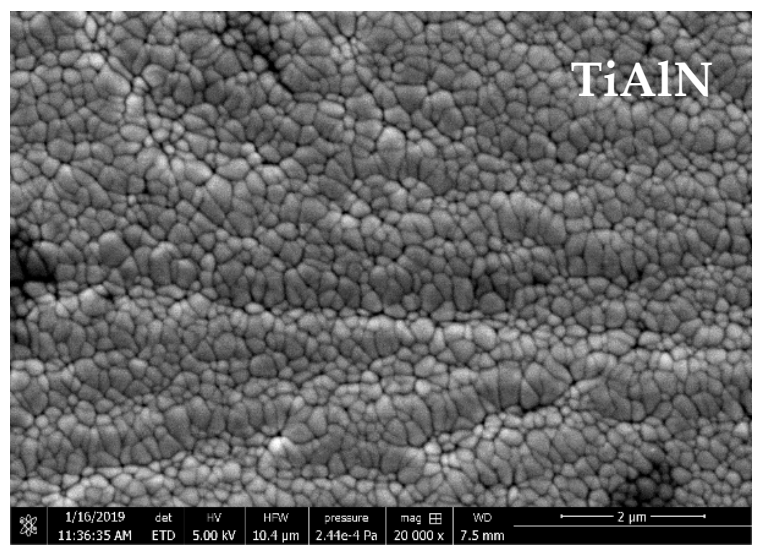

(a)

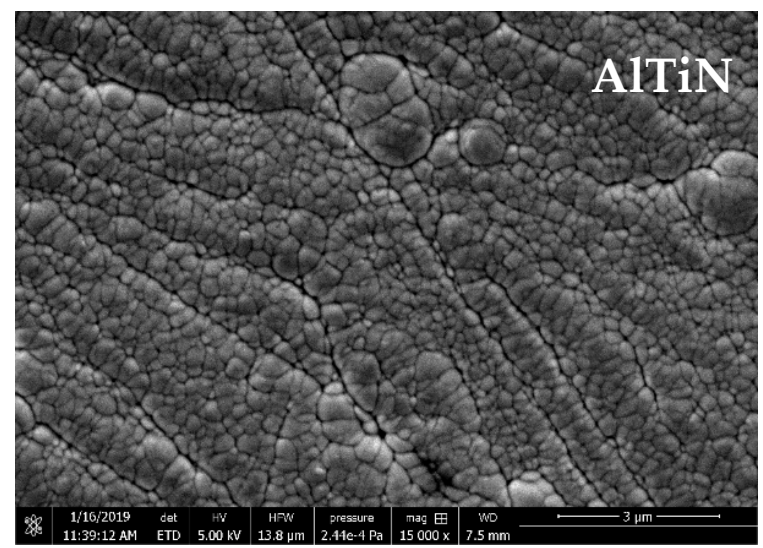

(b)

Figure 2. Surface of the PVD coatings: (a) TiAlN; (b) AlTiN, SEM.

Table 1. Results of SEM-EDS surface chemical composition spot analysis.

\begin{tabular}{|c|c|c|c|c|c|c|c|c|}
\hline \multirow{2}{*}{ Film } & \multirow{2}{*}{ Spot } & \multicolumn{7}{|c|}{ Chemical Element } \\
\hline & & $\operatorname{Ti}(w t \%)$ & $\mathrm{Al}(w \mathrm{t} \%)$ & $N(w t \%)$ & $\mathrm{Ti}(\mathrm{at} \%)$ & $\mathrm{Al}(\mathrm{at} \%)$ & N (at\%) & $\mathrm{Al} /(\mathrm{Ti}+\mathrm{Al})$ \\
\hline \multirow{4}{*}{ TiAlN } & 1 & 52.93 & 30.63 & 16.43 & 32.39 & 33.25 & 34.36 & 0.507 \\
\hline & 2 & 52.27 & 30.07 & 17.67 & 31.49 & 32.14 & 36.38 & 0.505 \\
\hline & 3 & 50.20 & 31.10 & 18.70 & 29.66 & 32.59 & 37.75 & 0.524 \\
\hline & Average & 51.80 & 30.60 & 17.60 & 31.16 & 32.66 & 36.18 & 0.512 \\
\hline \multirow{4}{*}{ AlTiN } & 1 & 41.93 & 35.63 & 22.43 & 23.06 & 34.77 & 42.17 & 0.601 \\
\hline & 2 & 43.30 & 35.10 & 21.60 & 24.14 & 34.71 & 41.15 & 0.590 \\
\hline & 3 & 44.97 & 35.47 & 19.57 & 25.73 & 36.00 & 38.27 & 0.583 \\
\hline & Average & 43.40 & 35.40 & 21.20 & 24.29 & 35.15 & 40.55 & 0.591 \\
\hline
\end{tabular}

Table 2. Film critical loads estimated by scratch test (Figure 3): Lc1—first symptoms of cohesive failure (angular or parallel cracking), Lc2 - beginning of adhesive failure (buckling, chipping, spalling, etc.), Lc3 - total failure of the coating or massive exposure of the substrate (mean $\pm \mathrm{SD}$ ).

\begin{tabular}{cccc}
\hline Film & Lc1 [N] & Lc2 [N] & Lc3 [N] \\
\hline TiAlN & $0.91 \pm 0.54$ & $7.23 \pm 1.19$ & $15.38 \pm 3.43$ \\
AlTiN & $0.91 \pm 0.61$ & $8.87 \pm 2.40$ & $18.93 \pm 4.76$ \\
\hline
\end{tabular}




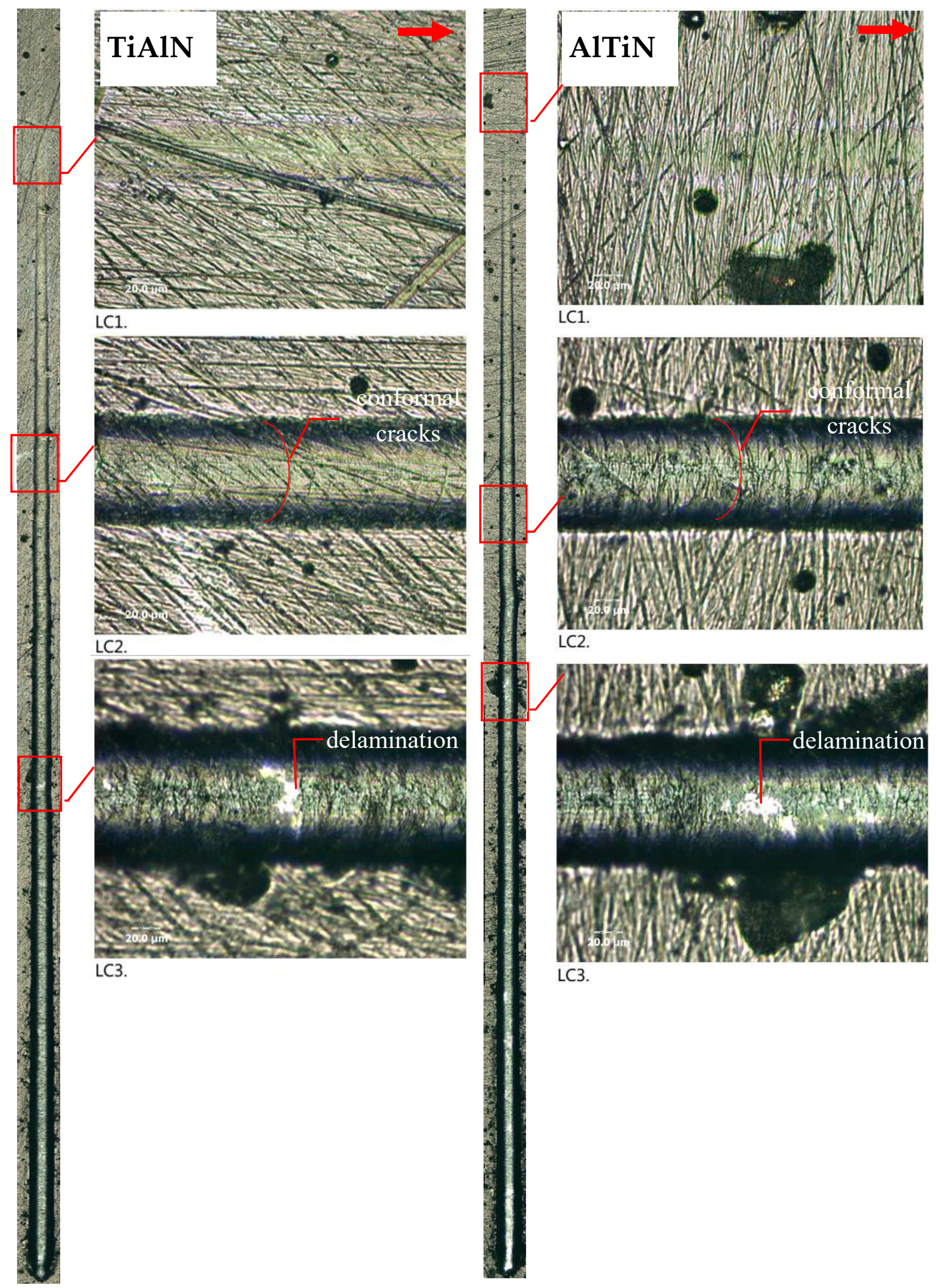

(a)

(b)

Figure 3. Scratch traces: (a) TiAlN; (b) AlTiN and enlarged characteristic areas of Lc1, Lc2 and Lc3. (total scratch trace $3 \mathrm{~mm}$ ), scratch direction marked by an arrow. 


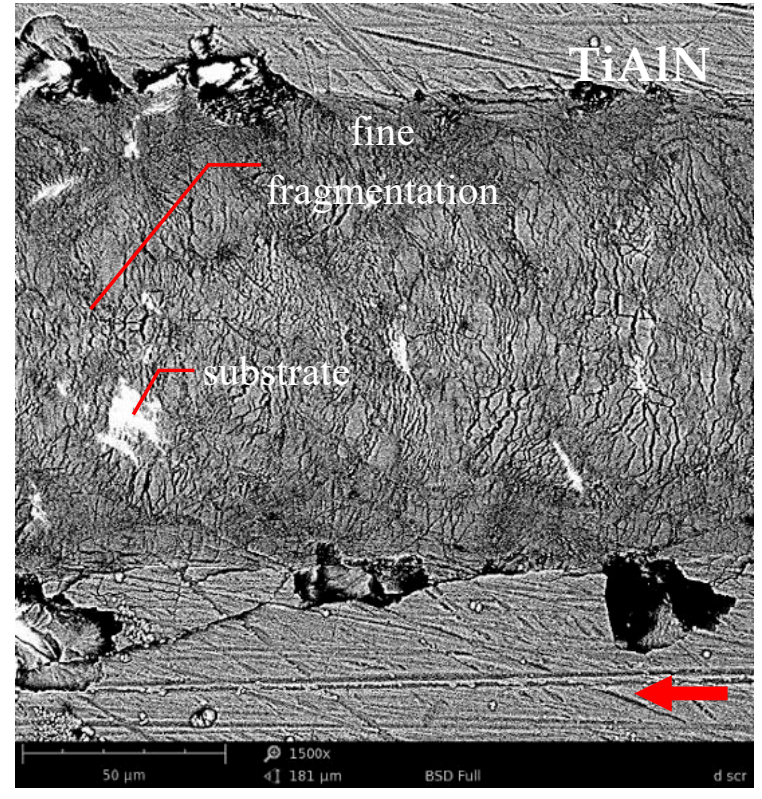

(a)

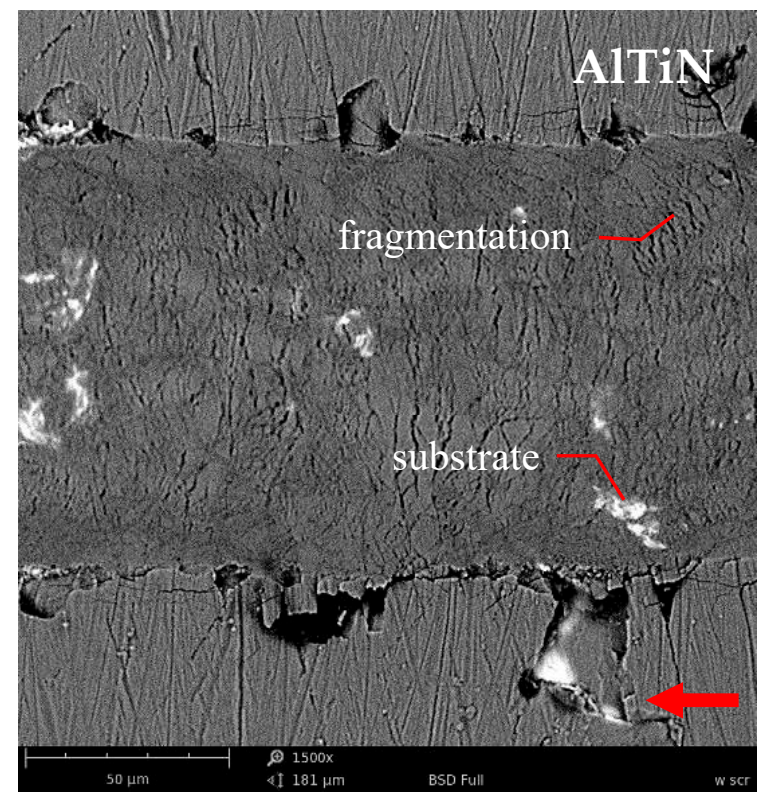

(b)

Figure 4. Comparison of the films at the end of the scratch trace, scratch direction marked by an arrow. (a) TiAlN; (b) AlTiN, magnif. 1500×, SEM.

In Figure 5, it is clearly visible that the AlTiN and TiAlN coatings have comparable elastic modulus and hardness, in the range of standard deviation. The $\mathrm{H}$ and $\mathrm{E}$ values are within the result range reported in the literature $[9,15,18,24]$. Nevertheless, AlTiN exhibits higher $\mathrm{H} / \mathrm{E}$ and $\mathrm{H}^{3} / \mathrm{E}^{2}$ ratios than TiAlN, which can be attributed to its higher Al content. Furthermore, the E and H of both films exceed those estimated for the SS substrate.

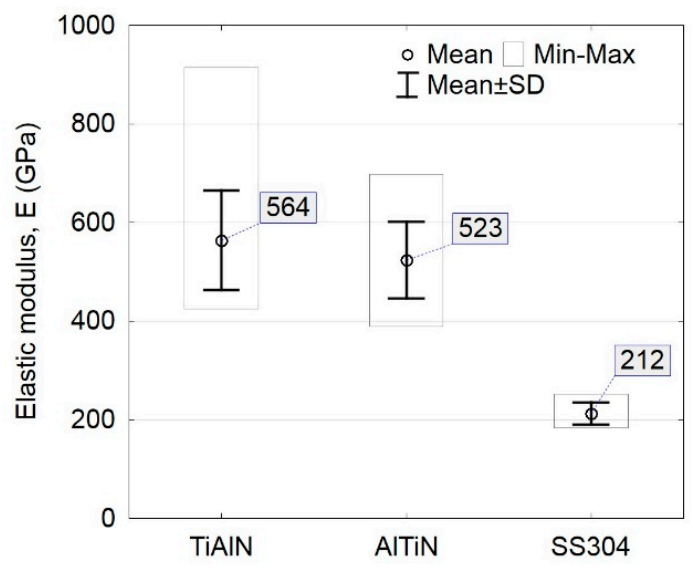

(a)

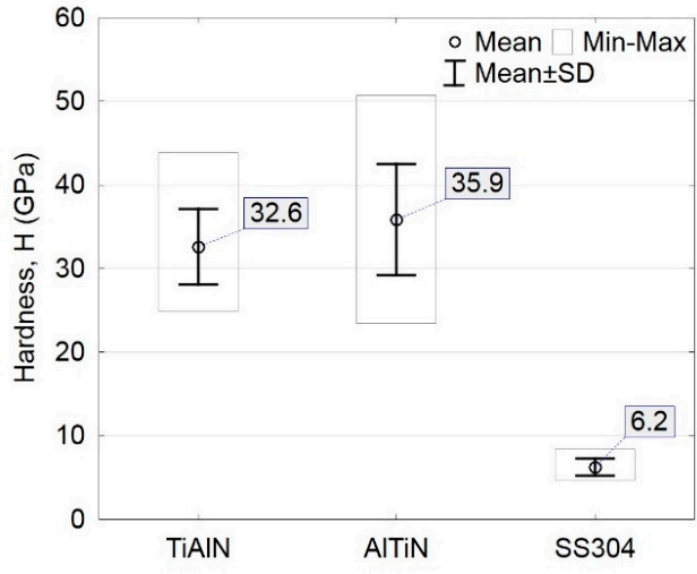

(b)

Figure 5. Elastic modulus and hardness of coated and bare SS304 samples. (a) elastic modulus; (b) hardness.

\subsection{Cavitaiton Erosion Resitance (CER)}

Quantitative results of the reference stainless steel (SS304) and the magnetron-sputtered AlTiN and TiAlN films deposited on the SS304 substrate are given in Figure 6, whereas a qualitative description of the erosion mechanism is discussed on the basis of Figures 7 and 8 Finally, Figure 9 and Table 3 present the effects of CE on the nanoindentation results, which is an original approach to CER evaluation.

The tested films exhibit higher CERs than the reference SS. The results indicate that the highest CER is achieved by the AlTiN coating, see Figure 6. These results strongly depend on the coating 
thickness, its mechanical properties and adhesion to the substrate. TiAlN has lower values of thickness, hardness and Lc2. Therefore, it can be deduced that these factors affect quantitative CE results. Also, the $\mathrm{H} / \mathrm{E}$ and $\mathrm{H}^{3} / \mathrm{E}^{2}$ coefficients increase and in turn, correlate well with the CER of the TiAlN and AlTiN coatings, which is a new approach to CER evaluation in ternary coating systems. It should be mentioned that a fairly good correlation between the above properties and CER in binary coating systems, i.e., TiN or CrN films, was also shown in the works of Krella [7,33], yet ternary element coatings have not been investigated previously.

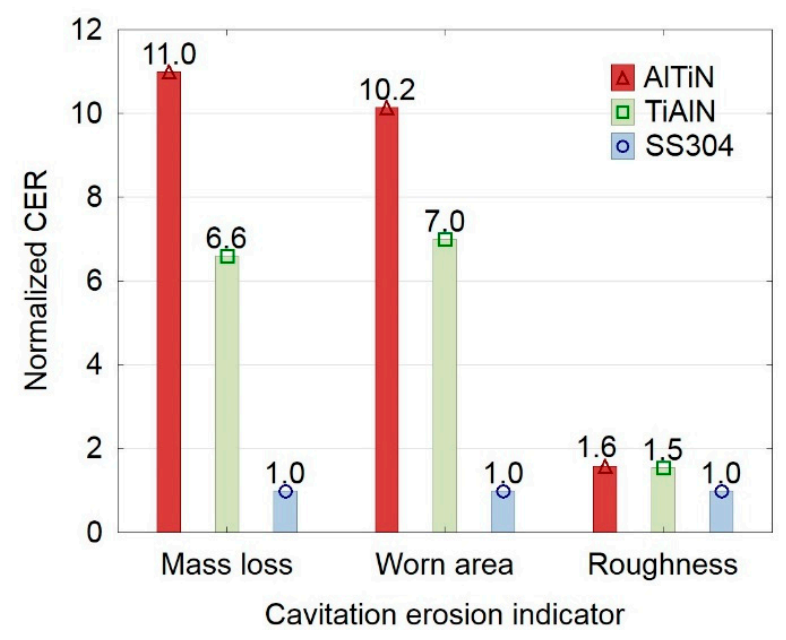

Figure 6. Cavitation erosion resistance (CER) calculated in reference to SS304 based on mass loss (mg), worn area percentage $(\%)$ and roughness parameter Sa $(\mu \mathrm{m}), 4.5 \mathrm{~h}$ of cavitation test.

\subsubsection{Mechanism of Cavitation Erosion Damage}

A survey of the literature reveals that there are few studies that compare the properties of TiAlN or AlTiN coatings in relation to their CER, and investigate the CE wear mechanism of magnetron-sputtered films with reference to an SS substrate. Figure 7a shows a macroscopic view of surface pitting and Figure $7 \mathrm{~b}$ compares the surface morphology of TiAlN, AlTiN and SS304 surfaces worn by cavitation erosion. The SEM photographs in Figure 8 provide details into cavitation erosion of the tested materials.

In general, the comparison of the worn surfaces agrees with the quantitative data presented in Figure 6. As a result of cavitation, the sample surfaces are randomly degraded due to the impact of micro-jets or shock pressure waves $[28,34,35]$. The TiAlN coating is severely more damaged and shows the presence of more pits in its structure than the AlTiN film (Figure 7a). In addition, the observed surface non-uniformities such as "scratches", resulting from substrate preparation, act as surface notches accelerating substrate-perpendicular cracking of the film and its rupture. Nevertheless, both films are less eroded than the reference sample. The roughness parameter Sa estimated for the damaged surfaces of TiAlN, AlTiN and SS304 is $1.5 \mu \mathrm{m}, 1.4 \mu \mathrm{m}$ and $2.3 \mu \mathrm{m}$, respectively (Figure $7 \mathrm{~b}$ ).

Measurable film mass losses were obtained after $4.5 \mathrm{~h}$ of testing. Thus, the incubation period of CE is approximately three times longer in the case of the hard films than that observed for the bare SS304 samples. This seems promising for increasing the operation time of real stainless steel components coated with magnetron-sputtered TiAlN or AlTiN films.

Generally, the CE mechanism of both AlTiN and AlTiN coatings is brittle by nature and depends on fatigue processes causing coating rupture and flake spallation (Figure 8). However, the deposited TiAlN and AlTiN coatings are much tougher (Figure 5) and brittle than the metal alloy substrate. The fatigue-dependent nature of the CE process causes steel substrate deformation, decreased film adhesion. Films cannot follow substrate deformation. The coating is first spalled and detached in random areas, which is followed by fatigue-induced decohesion of the film, see Figure 8 . Once the coating is detached, the density of cavitation pits in the bare surface increases, and the film-deprived areas allow the erosion process to continue into the SS substrate. This CE degradation mechanism 
observed for TiAlN and AlTiN is in agreement with the findings reported by Krella [7,16] for TiN films (deposited by the cathodic arc technique).
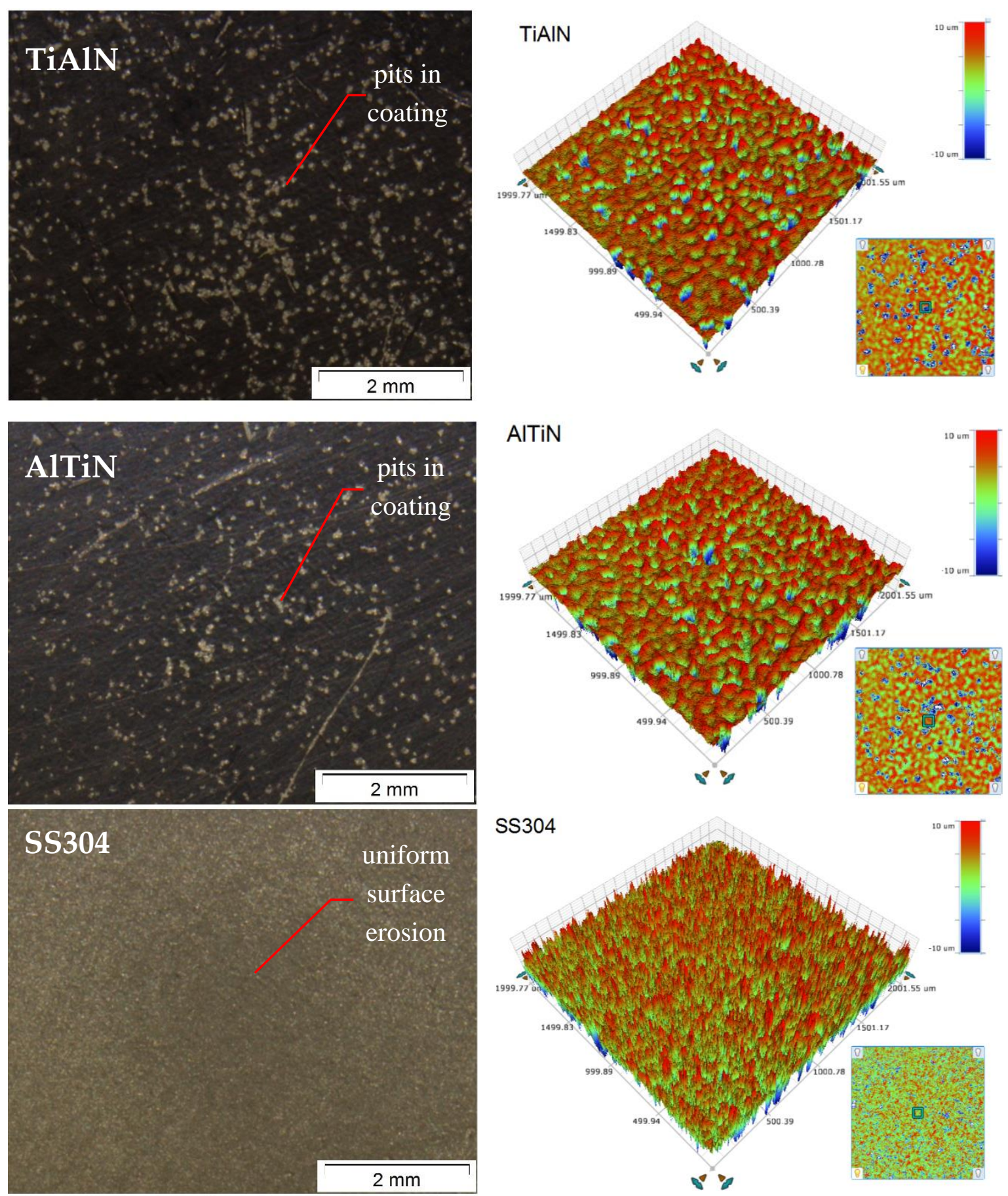

(a)

(b)

Figure 7. Macroscopic view of cavitation erosion-worn surface, stereoscopic microscope (a) and roughness profile of tested surfaces (b), after $4.5 \mathrm{~h}$ of cavitation testing.

The comparison between the cavitation-worn TiAlN and AlTiN films in pit areas, Figure 8, reveals that the degree of fragmentation is higher in TiAlN than AlTiN. This means that the removal of the fragmented TiAlN coating material is easier, which accelerates its mass loss. In both investigated films, the observed cracks usually propagate along the columnar grain packing, and the dominant $\mathrm{CE}$ 
mechanism is layer flake spallation of the film material. The above are novel findings in the field of $\mathrm{CE}$ mechanisms of magnetron-sputtered TiAlN and AlTiN films.

The erosion of the reference stainless steel sample surface is more extensive than that of the coatings, Figure 8. In contrast to the sputtered films, the SS304 surface shows developed damage combining deformation and uniform surface erosion, which is comparable with the results reported in the literature [34-36].

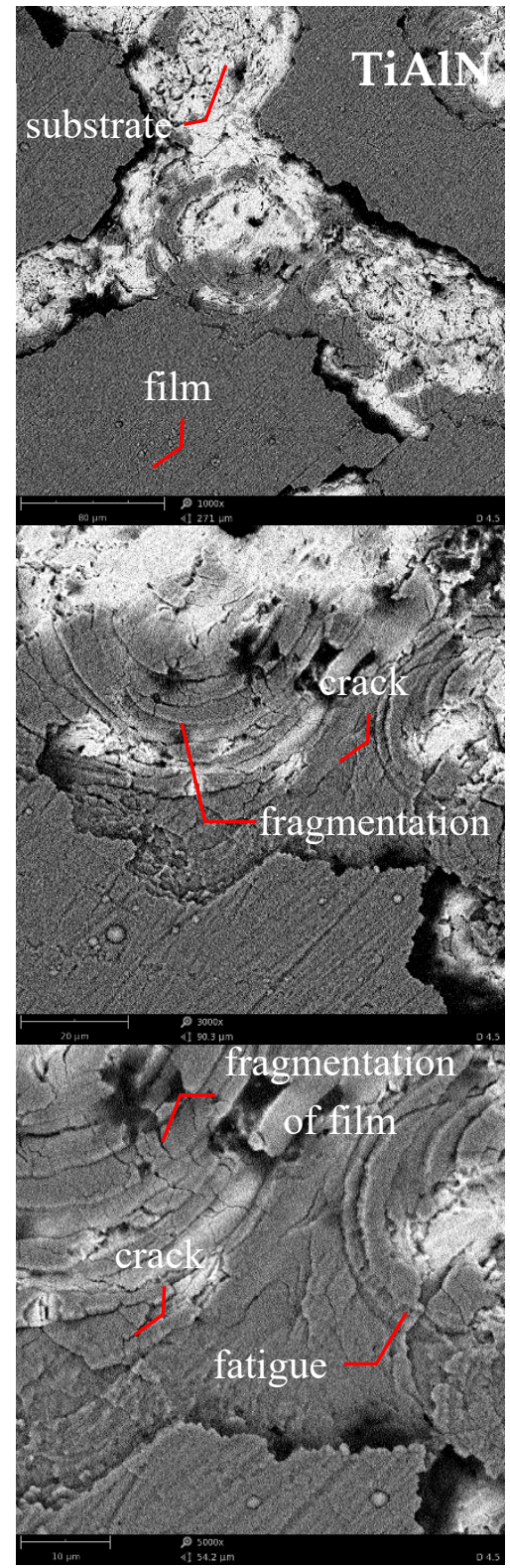

(a)

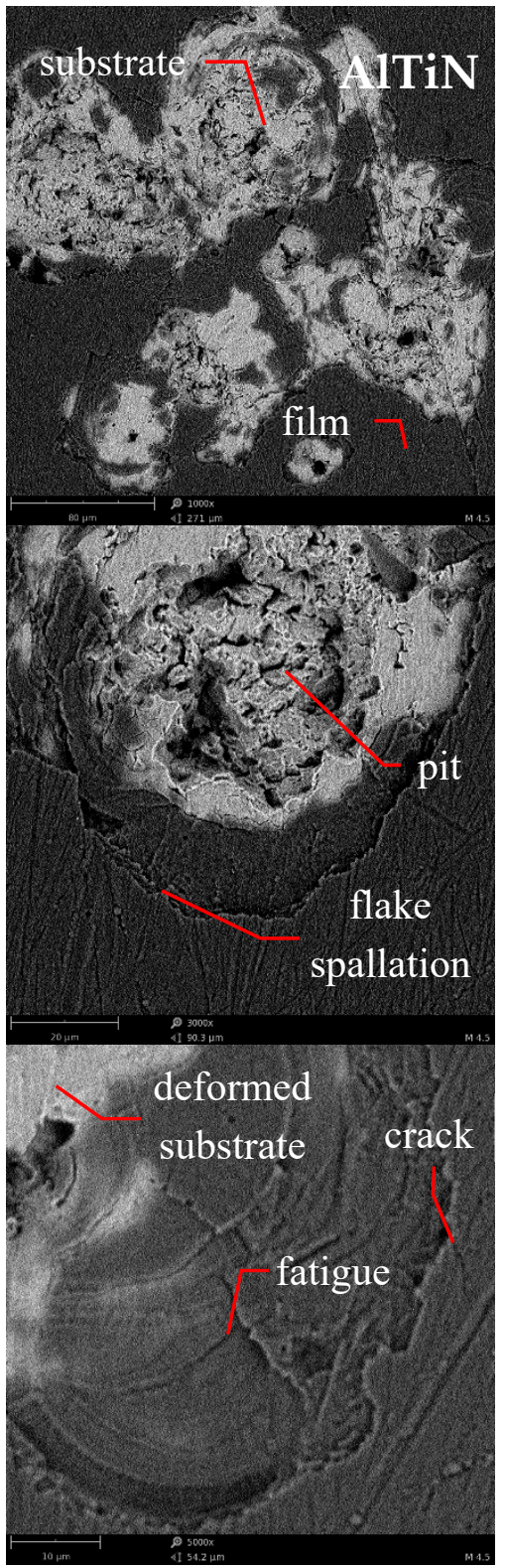

(b)

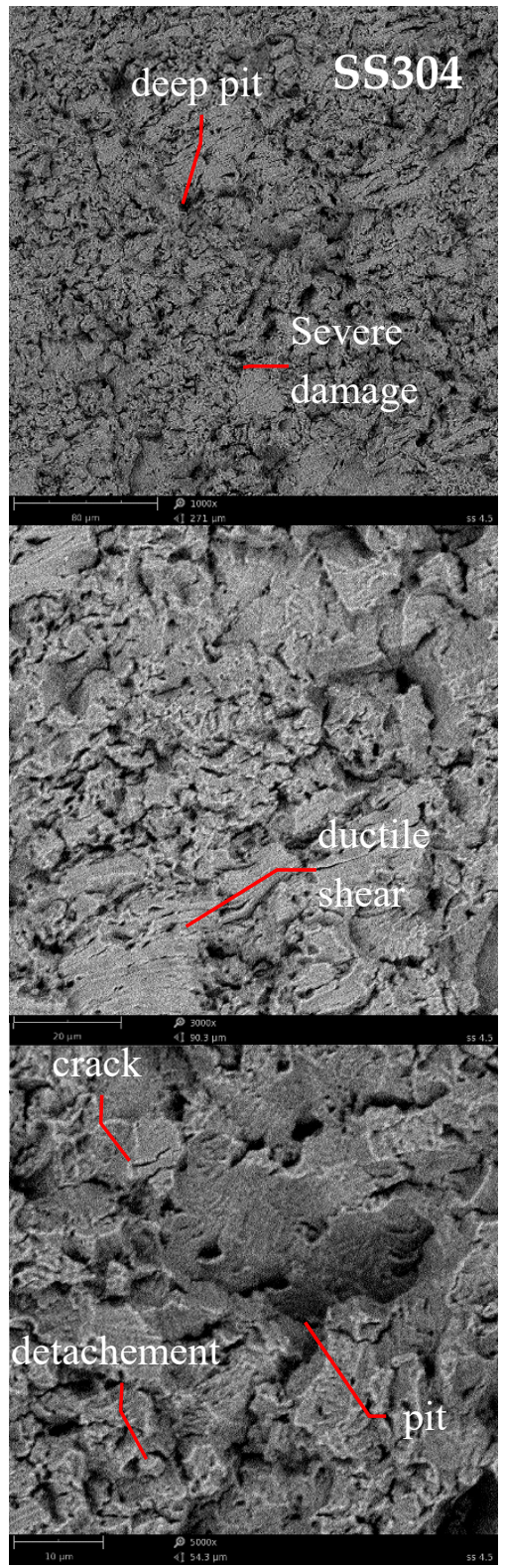

(c)

Figure 8. Comparison of cavitation-eroded thin films and stainless steel, after $4.5 \mathrm{~h}$ of testing: column (a) TiAlN; (b) AlTiN; (c) SS304; SEM, 1000×, 3000× and 5000×.

\subsubsection{Effect of Cavitation Erosion on Nanoindentation Results}

Nanoindentation measurements are a promising method of both CE wear mode identification and CER evaluation. Figure 9 and Table 3 give the results of nanoindentation measurements made before and after cavitation tests, which is a new approach to cavitation erosion testing of thin films. In contrast to the reference SS304 sample, AlTiN and TiAlN show a decrease in the hardness $H$ and the elastic 
modulus $E$ after the cavitation erosion tests (Table 3). This finding is in agreement with the results obtained for the SS304 sample, in which one of the first CE effects is usually an increase in surface hardness resulting from work hardening and/or cavitation load-induced phase transformation [34-37]. In the case of the films, however, there occurs fatigue-induced film decohesion occurs followed by the loss of film-substrate adhesion due to cavitation.

A promising method for the ternary films CER identification is to analyze mechanical properties, especially the $\mathrm{E} / \mathrm{H}$ and $\mathrm{H}^{3} / \mathrm{E}^{2}$ ratios estimated before cavitation (Table 3). According to the literature [38-42], the susceptibility of a material to elastic strain to failure is expressed by the $\mathrm{H} / \mathrm{E}$ quotient as well as its resistance to plastic deformation defined by the $\mathrm{H}^{3} / \mathrm{E}^{2}$ ratio. Higher $\mathrm{H} / \mathrm{E}$ and $\mathrm{H}^{3} / \mathrm{E}^{2}$ ratios mean that the films exhibit highly elastic behavior and high resistance to plastic deformation [38-41]. The high value of the $\mathrm{H}^{3} / \mathrm{E}^{2}$ coefficient is primarily attributed to fracture toughness of thin films. The AlTiN film has a higher $\mathrm{H}^{3} / \mathrm{E}^{2}$ ratio than the TiAlN film. In other words, the AlTiN coatings are considered to be more resistant than TiAlN, and hence much more resistant to cavitation erosion. This observation is in accordance with the normalized CER results, Figure 6.

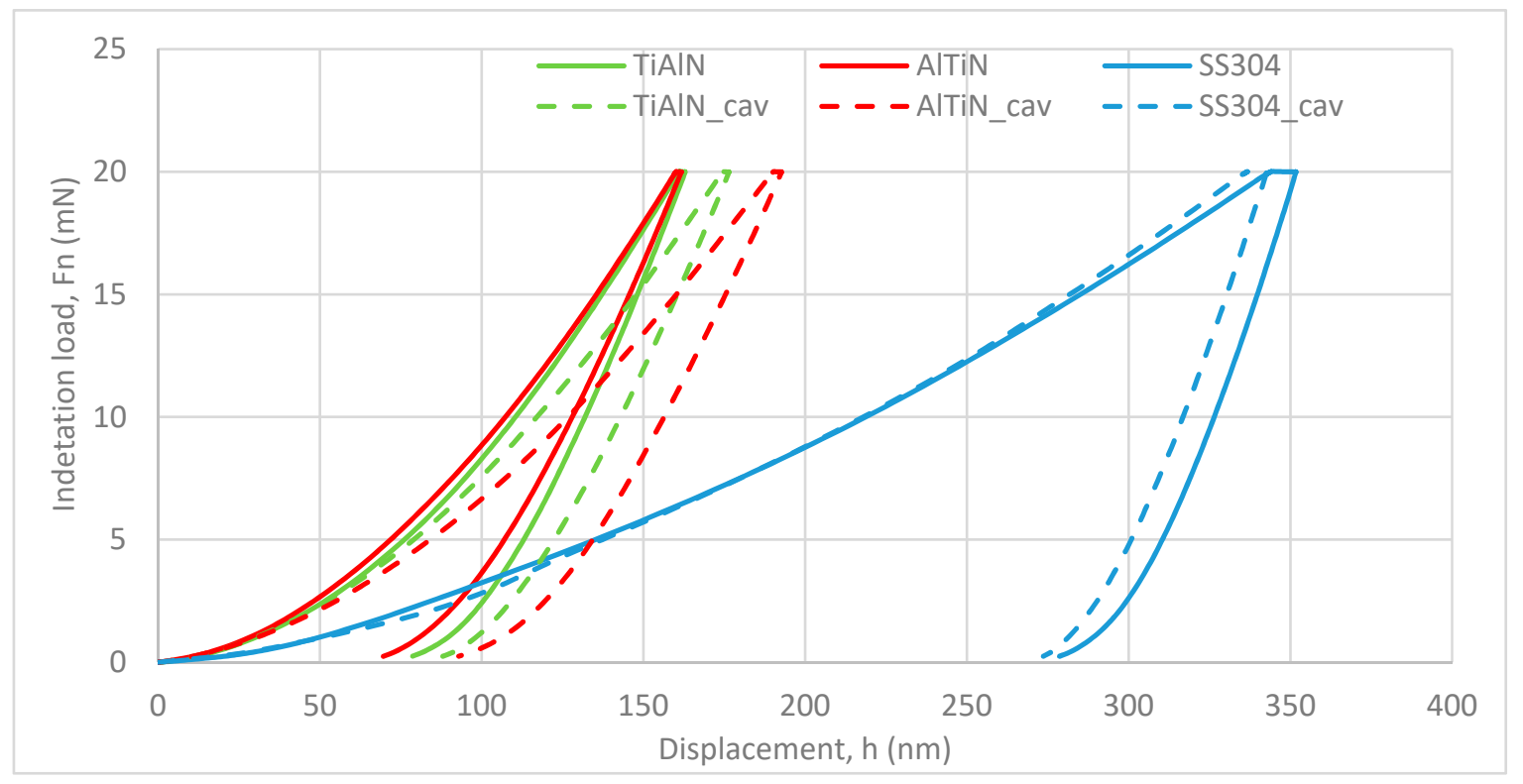

Figure 9. Loading-unloading nanoindentation curves estimated on the films and reference SS304 surface, before and after (marked as "cav") cavitation erosion tests.

Table 3. Results of hardness $(\mathrm{H})$ and elastic modulus (E) measured on the surface of samples before and after (marked as "cav") cavitation tests.

\begin{tabular}{ccccccc}
\hline \multirow{2}{*}{ Parameter } & \multicolumn{3}{c}{ Before Cavitation Test } & \multicolumn{3}{c}{ After Cavitation Test } \\
\cline { 2 - 6 } & SS304 & TiAlN & AlTiN & SS304_cav & TiAlN_cav & AlTiN_cav \\
\hline H $[\mathrm{GPa}]$ & $6.2 \pm 1.0$ & $31.0 \pm 4.9$ & $35.8 \pm 6.6$ & $6.7 \pm 0.3$ & $30.0 \pm 6.6$ & $25.4 \pm 5.0$ \\
E [GPa] & $212.4 \pm 22.7$ & $564.1 \pm 100.9$ & $523.3 \pm 77.9$ & $232.8 \pm 10.2$ & $452.1 \pm 76.9$ & $365.4 \pm 57.7$ \\
H/E & 0.029 & 0.059 & 0.068 & 0.029 & 0.066 & 0.070 \\
$\mathrm{H}^{3} / \mathrm{E}^{2}$ & $4.012 \times 10^{-6}$ & $6.067 \times 10^{-6}$ & $8.944 \times 10^{-6}$ & $3.558 \times 10^{-6}$ & $9.740 \times 10^{-6}$ & $1.322 \times 10^{-5}$ \\
\hline
\end{tabular}

\subsection{Sliding Wear Behaviour (Ball-on-disc Test)}

The ball-on-disc test employed in this study simulates real-life performance under low friction conditions. Quantitative results of the sliding wear test are given in Table 4 and Figure 10. The study has shown that both films present superior sliding wear results (the parameters $K$ and $\mu$, see Table 4 ) to the reference stainless steel sample. In general, in most engineering applications, the higher the $\mathrm{H} / \mathrm{E}$ and $\mathrm{H}^{3} / \mathrm{E}^{2}$ coefficients are, the higher the wear resistance of the coating should be $[18,42,43]$. However, 
in this study, the differences were also noted between the $\mathrm{H} / \mathrm{E}$ and $\mathrm{H}^{3} / \mathrm{E}^{2}$ coefficients of the films, although the resistance to sliding wear of AlTiN and TiAlN is similar (in the SD range, see Table 4). This observation can be explained by low load conditions of the hard films, which affects the relatively shallow wear trace plotted for both coatings, see Figure 10, resulting in a high measuring error of wear.

Furthermore, a qualitative analysis indicates that the SS304 sample undergoes severe sliding wear (see Figures 10a and 11) in comparison to the samples with the deposited TiAlN (Figure 12) and AlTiN (Figure 13). The stainless steel sample shows the presence of adhesive sliding wear and plastic deformation, ploughing with smearing, wear debris oxidation and grooving. Also, due to repeated upsetting and deformation of the material, flake shape delamination with debris transfer resulting from low-cycle fatigue are clearly visible, see Figure 11.

Since the AlTiN and TiAlN films have higher mechanical properties (Figure 5) and resistance to oxidation than the SS sample, their wear mechanism can be classified as grooving and microscratching with the presence of long scratches (Figures 12 and 13). Additionally, microploughing can be observed at the edges of the wear traces of both films. These scratches, groves and ploughs are especially visible in Figure 10b, in the form of non-symmetrical wear profiles. Moreover, the results of debris transfer through the sliding wear trace are visible, and — contrary to the SS sample-no oxidation can be observed in the film wear trace. It can be deduced from the film structures (Figure 2) with the wear trace observed at a higher magnification, see Figure 14, that the sliding wear mechanism consists in smearing the top hills of columnar grains. Generally, after the nano-tribo test conducted under moderate load, the films are pressed toward the SS substrate, and no nitride films delamination can be observed. To sum up, the TiAlN and AlTiN films have similar sliding wear mechanisms.

Table 4. Sliding wear results of the films and reference SS304 sample (mean \pm SD).

\begin{tabular}{ccc}
\hline Sample & Wear Factor, $\mathbf{K}\left(\mathbf{m m}^{\mathbf{3}} \cdot \mathbf{N}^{-\mathbf{1}} \cdot \mathbf{m}^{-\mathbf{1}}\right)$ & Coefficient of Friction, $\boldsymbol{\mu}(-)$ \\
\hline TiAlN & $1.35 \times 10^{-5} \pm 4.36 \times 10^{-6}$ & $0.319 \pm 0.037$ \\
AlTiN & $2.09 \times 10^{-5} \pm 3.49 \times 10^{-6}$ & $0.340 \pm 0.031$ \\
SS304 & $50.17 \times 10^{-5} \pm 61.52 \times 10^{-6}$ & $0.628 \pm 0.088$ \\
\hline
\end{tabular}

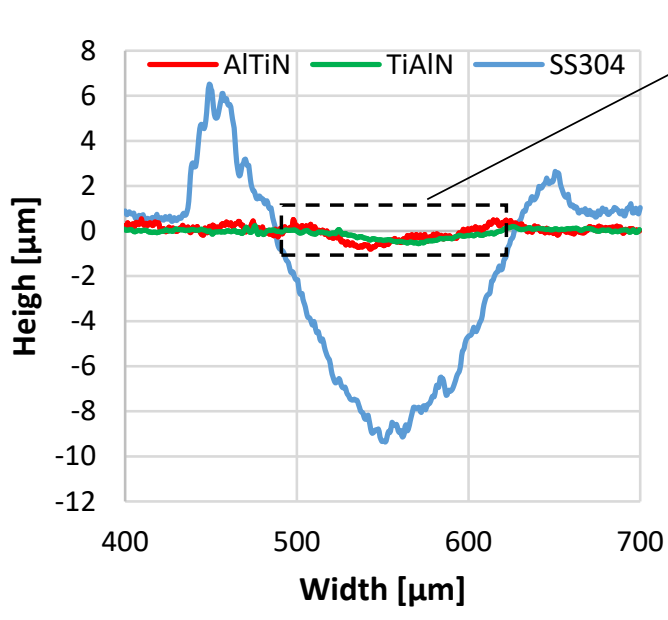

(a)

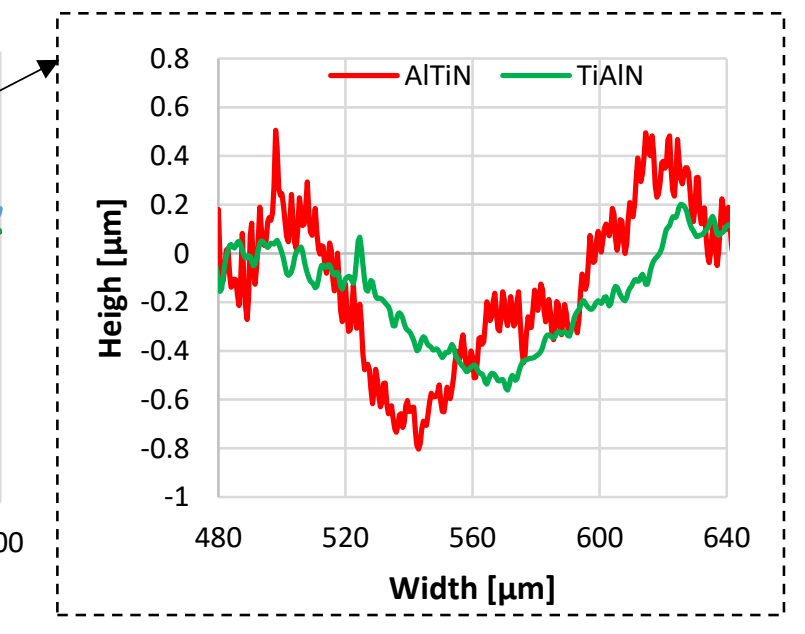

(b)

Figure 10. Sliding wear profiles: (a) films and stainless steel sample; (b) enlarged selected area of the TiAlN and AlTiN wear traces from (a). 


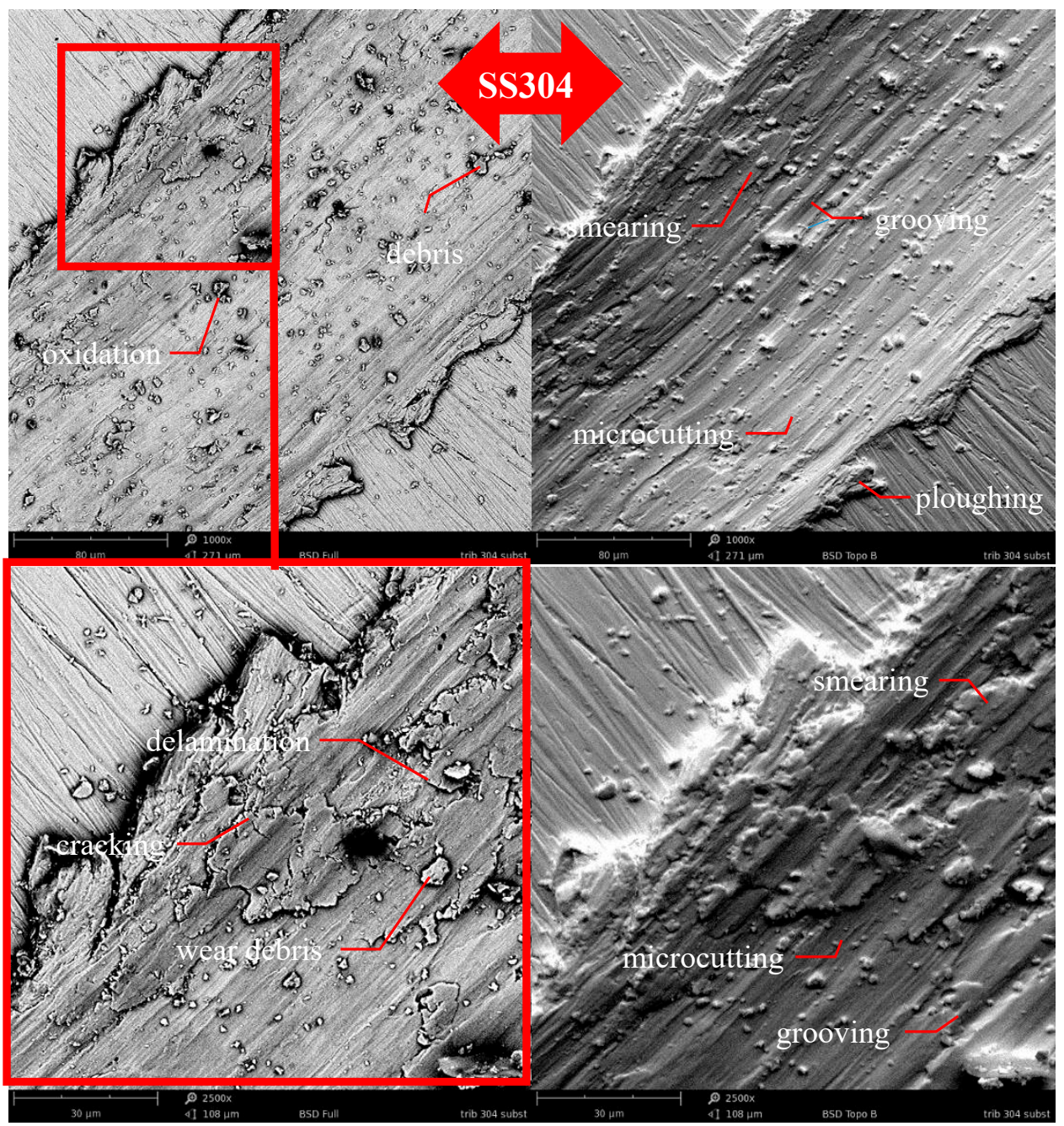

(a)

(b)

Figure 11. Wear trace on the SS304 sample: (a) SEM-BSD and (b) SEM-topo, 1000× and 2500×.

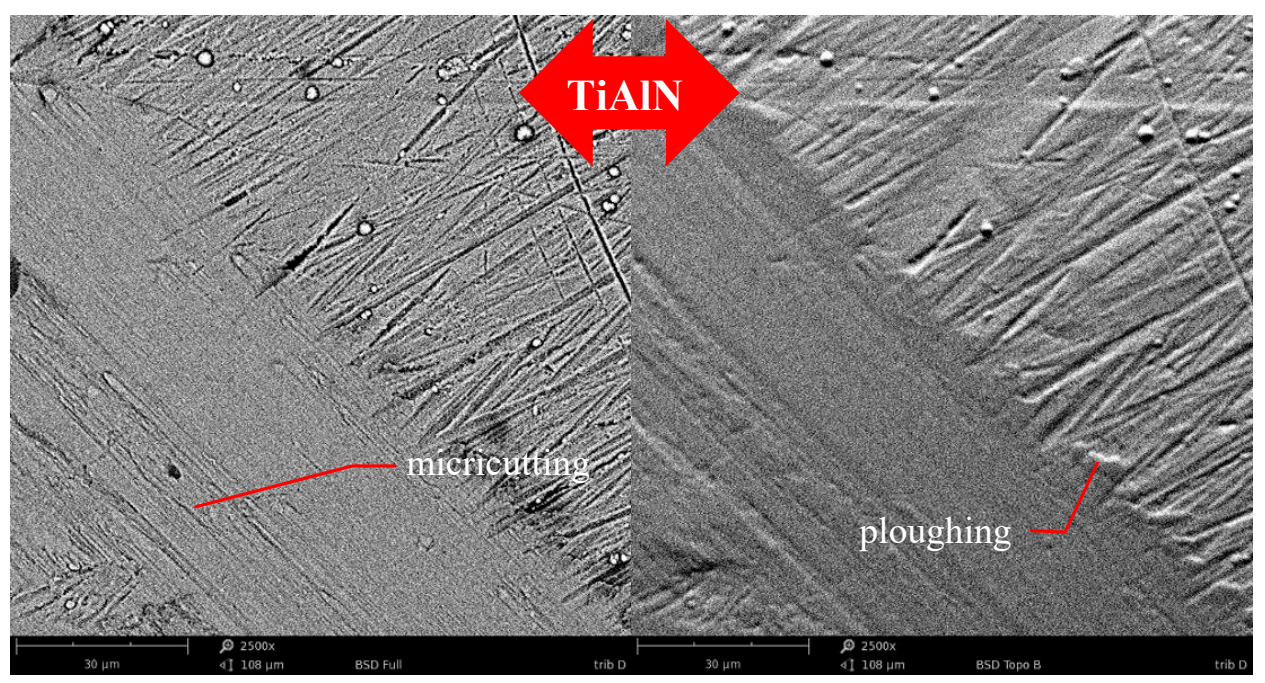

(a)

(b)

Figure 12. Wear trace on the TiAlN film: (a) SEM-BSD and (b) SEM-topo, 2500×. 


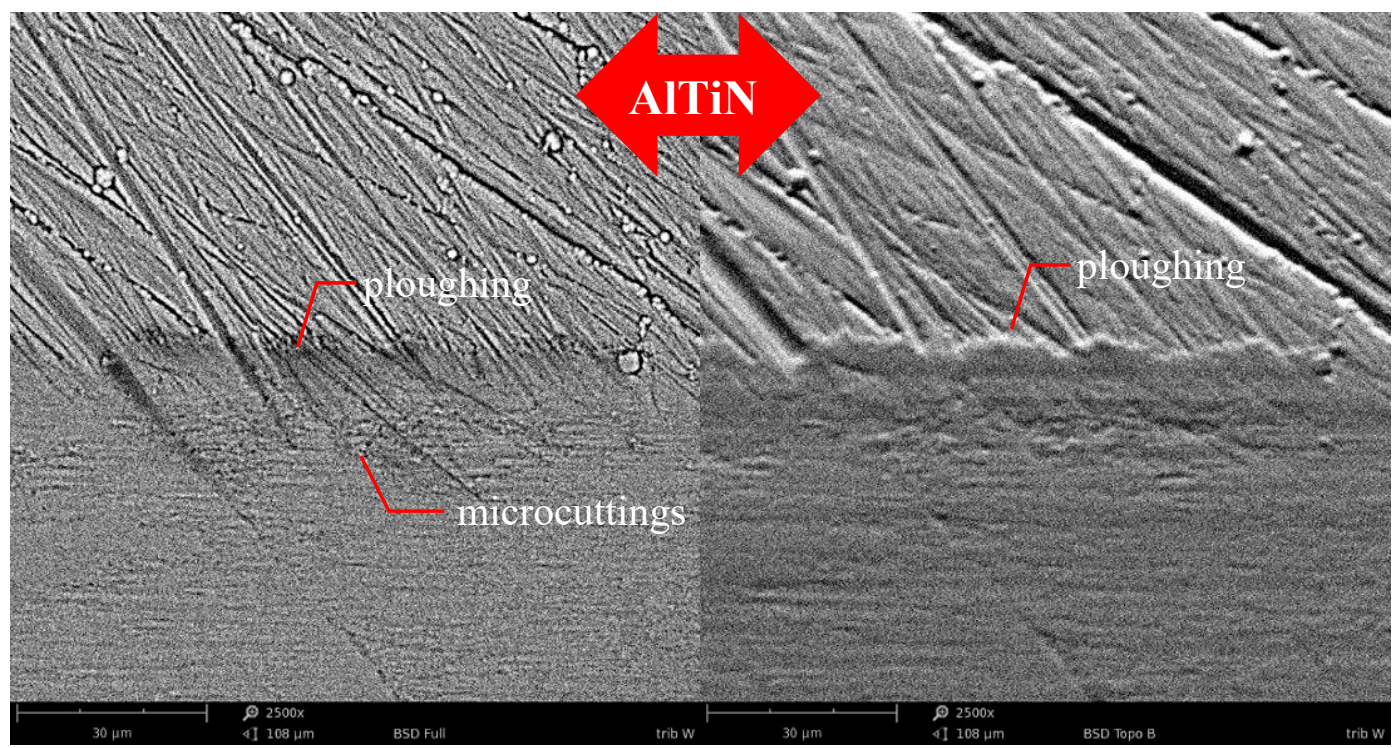

(a)

(b)

Figure 13. Wear trace on the AlTiN film: (a) SEM-BSD and (b) SEM-topo, 1000x and 2500x.

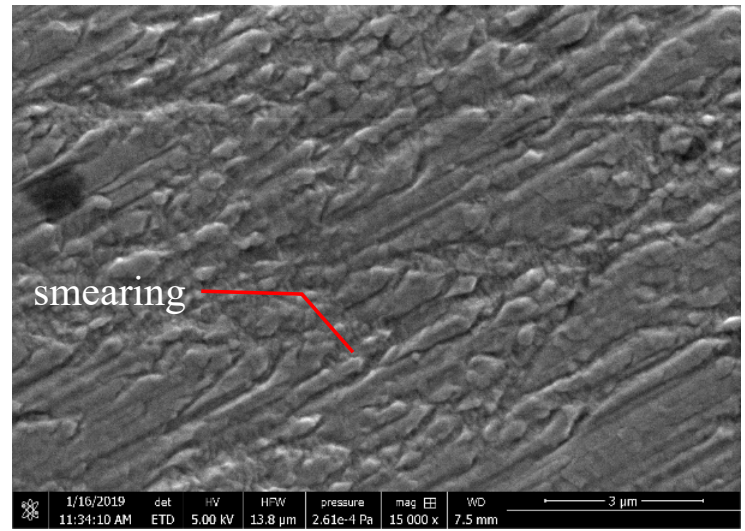

(a)

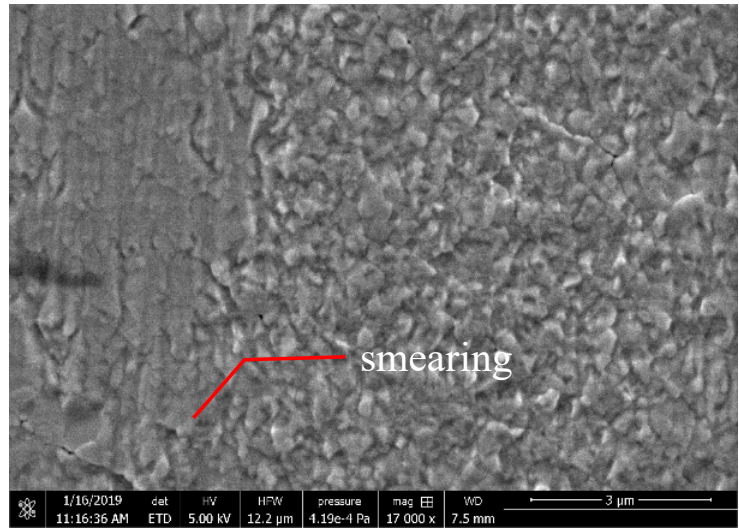

(b)

Figure 14. Sliding wear trace: (a) TiAlN; SEM, 15000×. and (b) AlTiN; SEM, 17000×.

\section{Conclusions}

Stainless steel is used for manufacturing different components and considered to be a structural metal with moderate resistance to cavitation erosion. The application of PVD coatings is proposed as a promising solution, easy to implement in industrial practice, for preventing the wear of stainless steel parts. In the present work, the cavitation erosion and sliding wear mechanism of magnetron-sputtered AlTiN and TiAlN coatings deposited on SS304 stainless steel (SS) were investigated. The following conclusions have been drawn:

1. The properties of the films demonstrate that they have a satisfactory structure, i.e., they exhibit a typical columnar morphology comparable to the roughness of the SS substrate, however it varies in thickness, amounting to $\approx 2.7 \mu \mathrm{m}$ for TiAlN and $\approx 3.8 \mu \mathrm{m}$ for AlTiN. Also, the Rockwell and scratch test results of the films indicate their satisfactory adhesion to the SS substrate, even though a higher force of the Lc2 parameters for AlTiN than TiAlN suggests that AlTiN adheres more strongly to the substrate. The AlTiN film exhibits highly elastic behavior and high resistance to plastic deformation, i.e., its $\mathrm{H} / \mathrm{E}$ and $\mathrm{H}^{3} / \mathrm{E}^{2}$ coefficients are higher than those of TiAlN, which can be attributed to its chemical composition, i.e., a higher $\mathrm{Al} /(\mathrm{Ti}+\mathrm{Al})$ ratio of the $\mathrm{AlTiN}$ film. 
2. The cavitation erosion resistance of AlTiN is almost one third higher than that of the TiAlN film and almost ten times higher than that of the SS304 sample. The effect of the chemical composition and mechanical properties of the films on their cavitation erosion resistance have been confirmed. The higher $\mathrm{Al}$ content, adhesion and $\mathrm{H} / \mathrm{E}$ and $\mathrm{H}^{3} / \mathrm{E}^{2}$ coefficients are beneficial for the CER of a film, and can thus serve as a basis for predicting the CER of AlTiN and AlTiN coatings.

3. The cavitation erosion mechanism of both AlTiN and AlTiN coatings is brittle in nature, and depends on fatigue processes that cause rupture and spallation of the coating. However, a comparison of the cavitation-worn TiAlN and AlTiN films reveals a higher degree of fragmentation of the TiAlN film, which ultimately accelerates the wear of the TiAlN film. Additionally, the nanoindentation results ( $\mathrm{H}$ and $\mathrm{E}$ ) of the films measured before and after cavitation testing indicate the presence of film material decohesion due to the fatigue-dependent nature of cavitation impact. The film wear mechanism consists in fatigue-induced flake spallation.

4. The sliding wear of the uncoated SS304 sample is higher than that of the sample after PVD coating. The sliding wear resistance of AlTiN and TiAlN is similar yet it is more than 24 times higher than that of the stainless steel sample. Additionally, the application of PVD films onto stainless steel substrates leads to an almost twofold decrease in the friction coefficient. The sliding wear mechanism of the AlTiN and TiAlN films takes the form of grooving, micro-scratching, micro-ploughing and smearing of the columnar grain top hills.

5. The results confirm that cavitation erosion of various fluid machinery components made of austenitic stainless steel can be prevented by depositing AlTiN and TiAlN films.

Author Contributions: Conceptualization, M.S.; Methodology, M.S.; Formal Analysis, M.S. and M.W.; Investigation, M.S., K.P. and M.K.; Writing-Original Draft Preparation, M.S.; Writing—Review \& Editing, M.S.; Visualization, M.S., K.P. and M.K.; Supervision, M.S. and M.W.

Funding: The research was financed in the framework of the project Lublin University of Technology-Regional Excellence Initiative, funded by the Polish Ministry of Science and Higher Education (contract No. 030/RID/2018/19).

Conflicts of Interest: The authors declare no conflict of interest.

\section{References}

1. Ha, H.-Y.; Jang, J.H.; Lee, T.-H.; Won, C.; Lee, C.-H.; Moon, J.; Lee, C.-G. Investigation of the localized corrosion and passive behavior of type 304 stainless steels with 0.2-1.8 wt \% B. Materials 2018, 11, 2097. [CrossRef]

2. $\quad$ Lawrynowicz, Z. Effect of the degree of cold work and sensitization time on intergranular corrosion behavior in austenitic stainless steel. Adv. Mater. Sci. 2019, 19, 32-43. [CrossRef]

3. España, P.C.; Recco, A.A.C.; Olaya, J.J. A microstructural and wear resistance study of stainless steel-ag coatings produced through magnetron sputtering. Coatings 2018, 8, 381.

4. Ha,H.-Y.; Lee, T.-H.; Bae, J.-H.; Chun, D.W. Molybdenum Effects on pitting corrosion resistance of fecrmnmonc austenitic stainless steels. Metals 2018, 8, 653. [CrossRef]

5. Szala, M.; Beer-Lech, K.; Walczak, M. A study on the corrosion of stainless steel floor drains in an indoor swimming pool. Eng. Fail. Anal. 2017, 77, 31-38. [CrossRef]

6. Wang, P.; Zhang, Y.; Yu, D. Microstructure and mechanical properties of pressure-quenched ss304 stainless steel. Materials 2019, 12, 290. [CrossRef]

7. Krella, A.K. The new parameter to assess cavitation erosion resistance of hard PVD coatings. Eng. Fail. Anal. 2011, 18, 855-867. [CrossRef]

8. Subramanian, B.; Umamaheswari, G.; Jayachandran, M. Properties and corrosion behaviour of reactive magnetron sputtered TiAlN coatings on AISI 316L SS in simulated bodily fluid. Corros. Eng. Sci. Technol. 2007, 42, 349-355. [CrossRef]

9. Chen, L.; Paulitsch, J.; Du, Y.; Mayrhofer, P.H. Thermal stability and oxidation resistance of Ti-Al-N coatings. Surf. Coat. Technol. 2012, 206, 2954-2960. [CrossRef]

10. Özkan, D. Friction behavior of TiAlN, AlTiN and AlCrN multilayer coatings at nanoscale. Erzincan Üniversitesi Fen Bilim. Enstitüsü Derg. 2018, 11, 451-458. [CrossRef] 
11. Hans, M.; Patterer, L.; Music, D.; Holzapfel, D.M.; Evertz, S.; Schnabel, V.; Stelzer, B.; Primetzhofer, D.; Völker, B.; Widrig, B.; et al. Stress-dependent elasticity of tialn coatings. Coatings 2019, 9, 24. [CrossRef]

12. Kulkarni, A.P.; Sargade, V.G. Characterization and performance of AlTiN, AlTiCrN, TiN/TiAlN PVD coated carbide tools while turning ss 304. Mater. Manuf. Process. 2015, 30, 748-755. [CrossRef]

13. Kohlscheen, J.; Bareiss, C. Effect of hexagonal phase content on wear behaviour of AlTiN Arc PVD coatings. Coatings 2018, 8, 72. [CrossRef]

14. Fan, Q.-X.; Wang, T.-G.; Liu, Y.-M.; Wu, Z.-H.; Zhang, T.; Li, T.; Yang, Z.-B. Microstructure and corrosion resistance of the AlTiN coating deposited by arc ion plating. Acta Metall. Sin. Engl. Lett. 2016, 29, 1119-1126. [CrossRef]

15. Shen, W.-J.; Tsai, M.-H.; Yeh, J.-W. Machining performance of sputter-deposited (Al0.34Cr0.22Nb0.11Si0.11Ti0.22)50N50 high-entropy nitride coatings. Coatings 2015, 5, 312-325. [CrossRef]

16. Krella, A.; Czyżniewski, A. Cavitation erosion resistance of nanocrystalline TiN coating deposited on stainless steel. Wear 2008, 265, 963-970. [CrossRef]

17. Itoh, T.; Hattori, S.; Lee, K.-Y. Cavitation erosion of 6061 aluminum alloy coated with TiAlN thin film. J. Solid Mech. Mater. Eng. 2010, 4, 1444-1454. [CrossRef]

18. Łepicka, M.; Grądzka-Dahlke, M.; Pieniak, D.; Pasierbiewicz, K.; Kryńska, K.; Niewczas, A. Tribological performance of titanium nitride coatings: A comparative study on TiN-coated stainless steel and titanium alloy. Wear 2019, 422-423, 68-80. [CrossRef]

19. Oliver, W.C.; Pharr, G.M. An improved technique for determining hardness and elastic modulus using load and displacement sensing indentation experiments. J. Mater. Res. 1992, 7, 1564-1583. [CrossRef]

20. Oliver, W.C.; Pharr, G.M. Measurement of hardness and elastic modulus by instrumented indentation: Advances in understanding and refinements to methodology. J. Mater. Res. 2004, 19, 3-20. [CrossRef]

21. Berg, G.; Friedrich, C.; Broszeit, E.; Berger, C. Development of chromium nitride coatings substituting titanium nitride. Surf. Coat. Technol. 1996, 86-87, 184-191. [CrossRef]

22. Mattox, D.M. Chapter 10: Film characterization and some basic film properties. In Handbook of Physical Vapor Deposition (PVD) Processing; Mattox, D.M., Ed.; William Andrew Publishing: Westwood, NJ, USA, 1998; pp. 569-615, ISBN 978-0-8155-1422-0.

23. Cai, F.; Huang, X.; Yang, Q. Mechanical properties, sliding wear and solid particle erosion behaviors of plasma enhanced magnetron sputtering CrSiCN coating systems. Wear 2015, 324-325, 27-35. [CrossRef]

24. Walczak, M.; Pasierbiewicz, K.; Szala, M. Adhesion and mechanical properties of TiAlN and AlTiN magnetron sputtered coatings deposited on DMSL titanium alloy substrate. Acta Phys. Pol. A 2019, in press.

25. Vidakis, N.; Antoniadis, A.; Bilalis, N. The VDI 3198 indentation test evaluation of a reliable qualitative control for layered compounds. J. Mater. Process. Technol. 2003, 143-144, 481-485. [CrossRef]

26. ASTM G32-10: Standard Test Method for Cavitation Erosion Using Vibratory Apparatus; West Conshohocken: Philadelphia, PA, USA, 2010.

27. Szala, M.; Hejwowski, T. Cavitation erosion resistance and wear mechanism model of flame-sprayed $\mathrm{Al} 2 \mathrm{O} 3-40 \% \mathrm{TiO} 2 \mathrm{NiMoAl}$ cermet coatings. Coatings 2018, 8, 254. [CrossRef]

28. Szala, M. Application of computer image analysis software for determining incubation period of cavitation erosion-Preliminary results. EDP Sci. 2017, 15, 06003. [CrossRef]

29. Budzyński, P.; Kamiński, M.; Wiertel, M.; Pyszniak, K.; Droździel, A. Mechanical properties of the stellite 6 cobalt alloy implanted with nitrogen ions. Acta Phys. Pol. A 2017, 132, 203-205. [CrossRef]

30. Kamiński, M.; Budzyński, P.; Szala, M.; Turek, M. Tribological properties of the Stellite 6 cobalt alloy implanted with manganese ions. IOP Conf. Ser. Mater. Sci. Eng. 2018, 421, 032012. [CrossRef]

31. Walczak, M.; Pieniak, D.; Niewczas, A.M. Effect of recasting on the useful properties CoCrMoW alloy. Eksploat. Niezawodn. Maint. Reliab. 2014, 16, 330-336.

32. Kalss, W.; Reiter, A.; Derflinger, V.; Gey, C.; Endrino, J.L. Modern coatings in high performance cutting applications. Int. J. Refract. Met. Hard Mater. 2006, 24, 399-404. [CrossRef]

33. Krella, A. The influence of TiN coatings properties on cavitation erosion resistance. Surf. Coat. Technol. 2009, 204, 263-270. [CrossRef]

34. Hattori, S.; Mikami, N. Cavitation erosion resistance of stellite alloy weld overlays. Wear 2009, 267, $1954-1960$. [CrossRef] 
35. Mesa, D.H.; Garzón, C.M.; Tschiptschin, A.P. Influence of cold-work on the cavitation erosion resistance and on the damage mechanisms in high-nitrogen austenitic stainless steels. Wear 2011, 271, 1372-1377. [CrossRef]

36. Wu, Y.; Hong, S.; Zhang, J.; He, Z.; Guo, W.; Wang, Q.; Li, G. Microstructure and cavitation erosion behavior of WC-Co-Cr coating on $1 \mathrm{Cr} 18 \mathrm{Ni}$ Ti stainless steel by HVOF thermal spraying. Int. J. Refract. Met. Hard Mater. 2012, 32, 21-26. [CrossRef]

37. Szala, M. Coatings for Increasing Cavitation Wear Resistance of Machine Parts and Elements. Ph.D. Thesis, Lublin University of Technology, Lublin, Poland, 2016.

38. Lee, S.-C.; Ho, W.-Y.; Lai, F.D. Effect of substrate surface roughness on the characteristics of CrN hard film. Mater. Chem. Phys. 1996, 43, 266-273. [CrossRef]

39. Johnson, K.L.; Johnson, K.L. Contact Mechanics; Cambridge University Press: Cambridge, UK, 1987; ISBN 978-0-521-34796-9.

40. Tsui, T.Y.; Pharr, G.M.; Oliver, W.C.; Bhatia, C.S.; White, R.L.; Anders, S.; Anders, A.; Brown, I.G. Mechanical behavior of diamond and other forms of carbon. Mater. Res. Soc. Symp. Proc. 1995, 383, 447. [CrossRef]

41. Musil, J.; Kunc, F.; Zeman, H.; Poláková, H. Relationships between hardness, Young's modulus and elastic recovery in hard nanocomposite coatings. Surf. Coat. Technol. 2002, 154, 304-313. [CrossRef]

42. Leyland, A.; Matthews, A. On the significance of the H/E ratio in wear control: a nanocomposite coating approach to optimised tribological behaviour. Wear 2000, 246, 1-11. [CrossRef]

43. Solis, J.; Zhao, H.; Wang, C.; Verduzco, J.A.; Bueno, A.S.; Neville, A. Tribological performance of an H-DLC coating prepared by PECVD. Appl. Surf. Sci. 2016, 383, 222-232. [CrossRef]

(C) 2019 by the authors. Licensee MDPI, Basel, Switzerland. This article is an open access article distributed under the terms and conditions of the Creative Commons Attribution (CC BY) license (http://creativecommons.org/licenses/by/4.0/). 